\title{
Effort angina with an anomalous origin of the left circumflex coronary artery
}

\author{
Mitsumasa Okano, Takao Kato, Moriaki Inoko
}

Department of Cardiovascular Medicine, The Tazuke Kofukai Medical Research Institute, Kitano Hospital, Osaka, Japan

\section{Correspondence to}

Dr Takao Kato,

takao-kato@kitano-hp.or.jp

Accepted 12 November 2014

\section{DESCRIPTION}

A 61-year-old man with hypertension and dyslipidemia presented with exertional chest pain that improved after the administration of nitric oxide. A treadmill exercise ECG demonstrated down-sloping ST-segment depression in leads V4-V6 without chest pain (figure 1A, B). Stress myocardial perfusion scintigraphy revealed a lateral ischaemia (figure 1C). Coronary angiography revealed no significant stenosis in the left anterior descending artery (figure $2 \mathrm{~A}, \mathrm{~B}$ ), and a deficit of the left circumflex coronary artery (LCX) apparently. A careful re-examination of the angiography images revealed coronary flow of the LCX at the time of administration of contrast to the right coronary artery (RCA; figure 2C, D). The patient underwent cardiac CT scan for further evaluation of LCX. The
CT scan identified an anomalous origin of the LCX arising from the right sinus of Valsalva near the RCA origin, with an extramural course between the aorta and the left atrium (figure $3 \mathrm{~A}-\mathrm{C}$ ). It passed along the left atrioventricular groove and perfused the lateral wall. The proximal portion of the anomalous LCX was 75\% occluded (figure 3D-E). We inferred that the anomalous LCX was the culprit artery. The patient was treated with $5 \mathrm{mg}$ of carvedilol daily, and the symptom improved. The prevalence of anomalous origin of the LCX was reported to be $0.17 \%{ }^{1}$ and the slit-like orifice and a narrow intramural distal artery might be an important cause of ischaemia. $^{2}{ }^{3}$ In our case, cardiac CT and exercise-stress testing identified the anomalous LCX and its atherosclerotic lesion in the long mid-portion as a cause of the patient's angina.

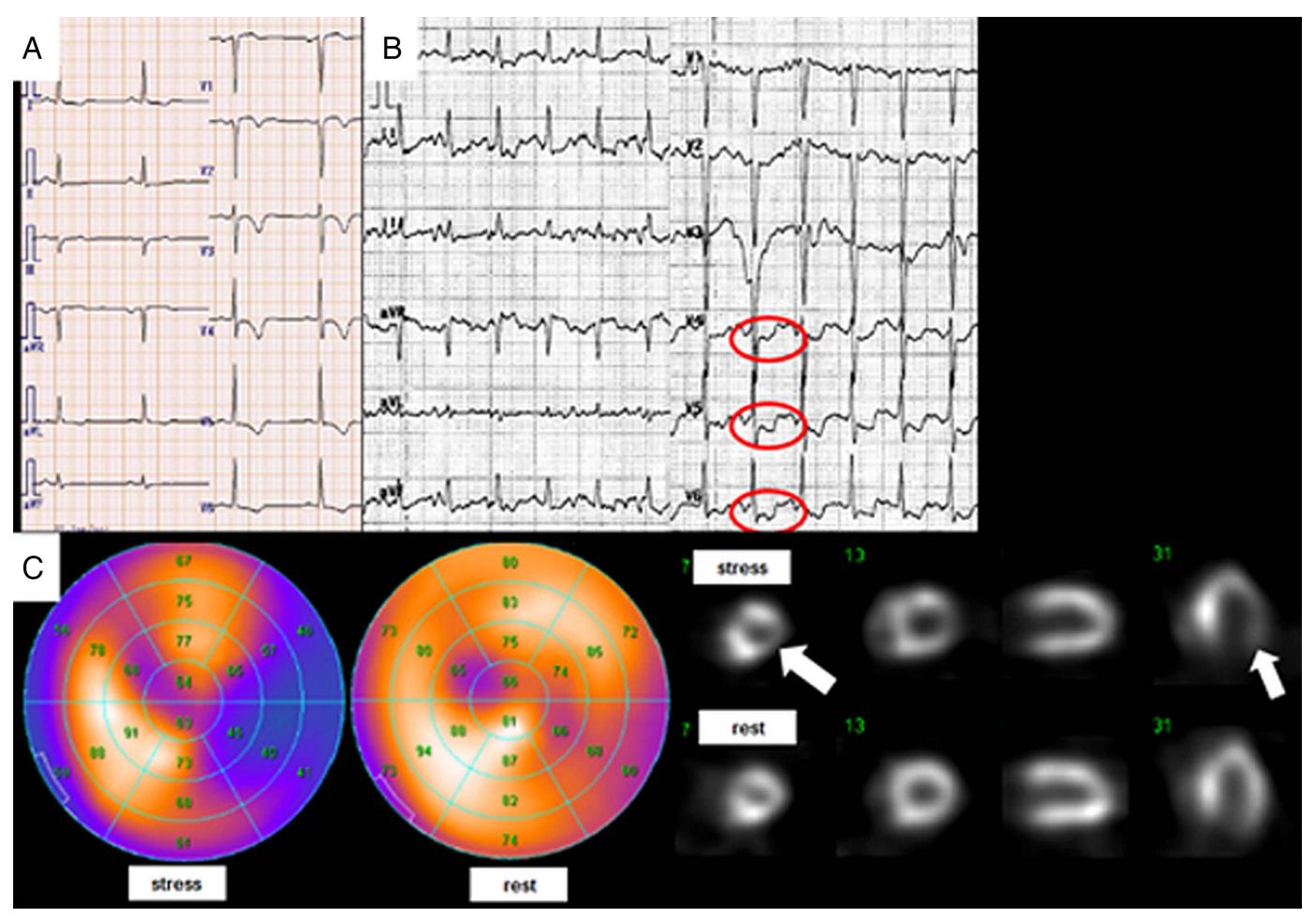

Figure 1 (A) ECG at rest. (B) An exercise-stress ECG. (C) Exercise-stress myocardial perfusion imaging using thallium-201 revealed lateral ischaemia during exercise. Right two panels: polar maps of myocardial perfusion. White 


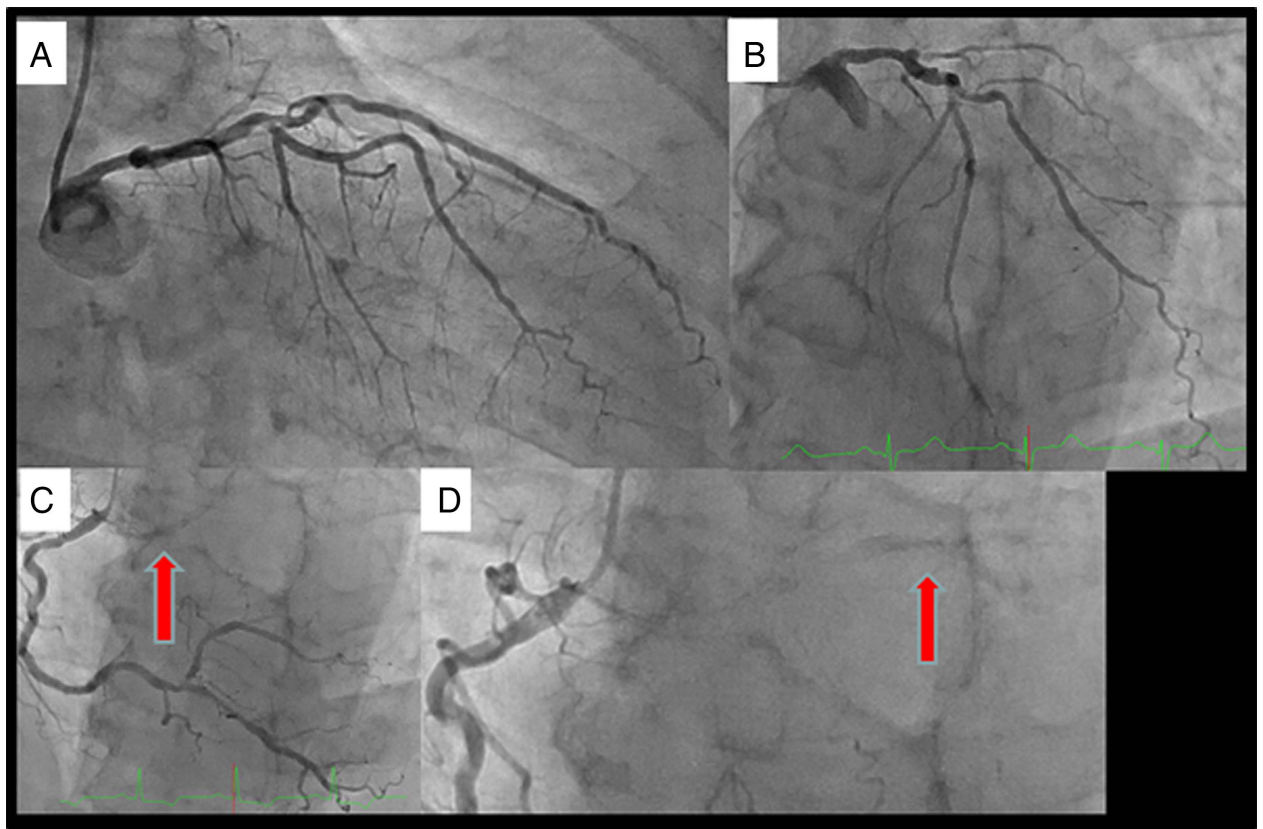

Figure 2 (A) Caudal $30^{\circ}$, (B) right anterior oblique (RAO) $30^{\circ}$ cranial $30^{\circ}$, (C) RAO $30^{\circ}$ cranial $30^{\circ}$ and (D) a careful re-examination of the angiography images revealing coronary flow in the perfusion area of the LCX (indicated by red arrows) at the time of administration of contrast to the right coronary artery.
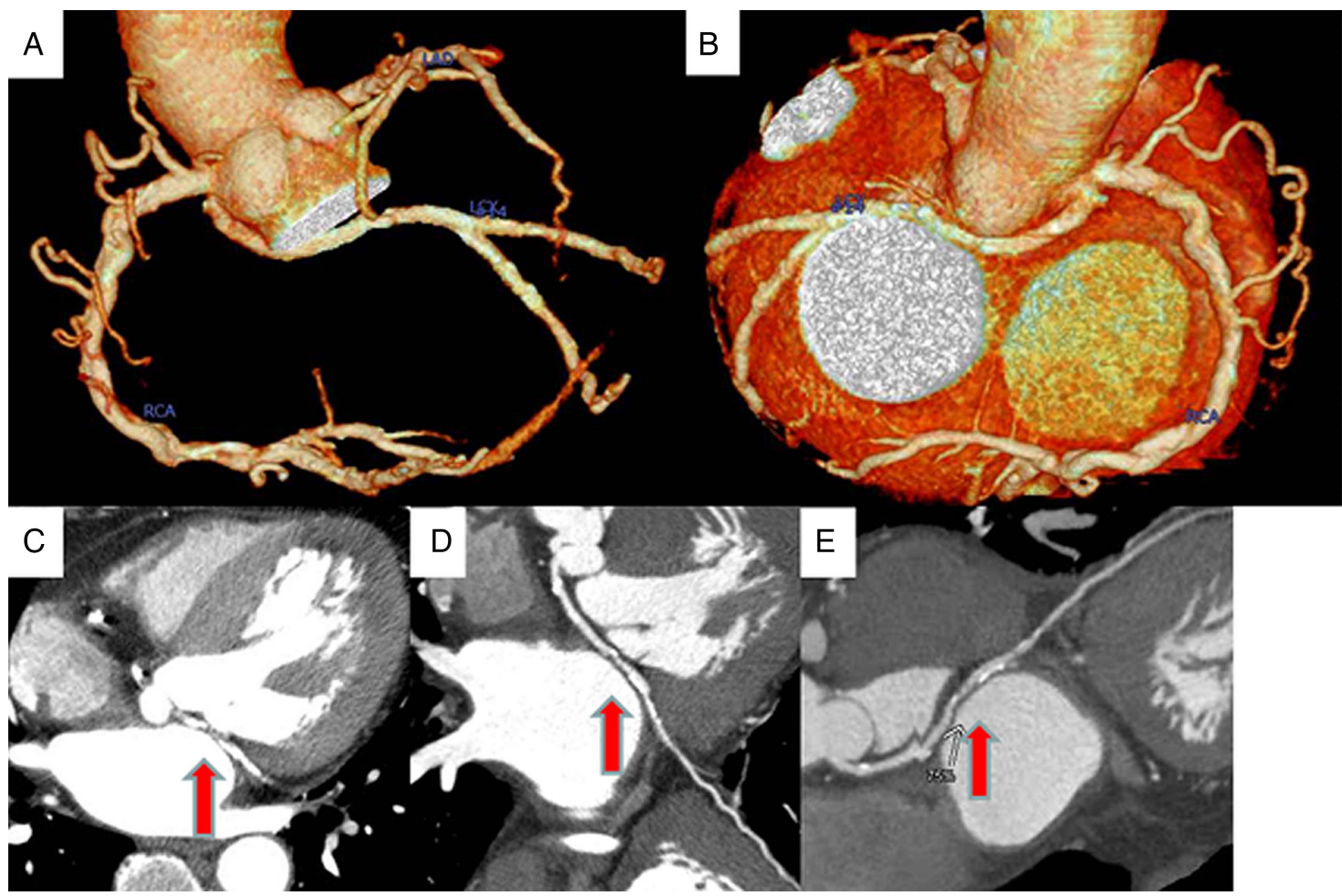

Figure 3 Coronary CT showing the anomalous origin of the left circumflex (LCX) arising from the right sinus of Valsalva near the right coronary artery origin (A and B). LCX run between the aorta and the left atrium. It passed along the left atrioventricular groove and perfused the lateral wall (C, D, and E) with atherosclerotic stenosis (arrows). 


\section{Learning points}

- A vascular area of one branch of coronary artery requires a high level of suspicion of an anomalous origin of a coronary artery.

- Cardiac CT scan is a useful non-invasive modality that can be employed for the morphological assessment of and devising treatment for coronary artery diseases, particularly in cases with anomalous coronary arteries.

- The slit-like orifice and a narrow intramural distal artery, which is longer than normal morphology and, possibly, more susceptible for atherosclerosis burden, might be an important cause of ischaemia in cases with anomalous coronary arteries.
Contributors $\mathrm{MO}$ and TK wrote the manuscript and $\mathrm{Ml}$ supervised it.

Competing interests None.

Patient consent Obtained.

Provenance and peer review Not commissioned; externally peer reviewed.

\section{REFERENCES}

1 Yamanaka O, Hobbs RE. Coronary artery anomalies in 126,595 patients undergoing coronary arteriography. Cathet Cardiovasc Diagn 1990;21:28-40.

2 Taylor AJ, Byers JP, Cheitlin MD, et al. Anomalous right or left coronary artery from the contralateral coronary sinus: "high-risk" abnormalities in the initial coronary artery course and heterogeneous clinical outcomes. Am Heart J 1997:133:428-35.

3 Carboni GP, Sedati P. A rare, life-threatening effort angina and anomalous origin of the left circumflex coronary artery: CT and SPECT findings. BMJ Case Rep 2013;2013:pii: bcr2013009005.

Copyright 2014 BMJ Publishing Group. All rights reserved. For permission to reuse any of this content visit http://group.bmj.com/group/rights-licensing/permissions.

BMJ Case Report Fellows may re-use this article for personal use and teaching without any further permission.

Become a Fellow of BMJ Case Reports today and you can:

- Submit as many cases as you like

- Enjoy fast sympathetic peer review and rapid publication of accepted articles

- Access all the published articles

- Re-use any of the published material for personal use and teaching without further permission

For information on Institutional Fellowships contact consortiasales@bmjgroup.com

Visit casereports.bmj.com for more articles like this and to become a Fellow 